\title{
Peripheral airway findings in chronic obstructive pulmonary disease using an ultrathin bronchoscope
}

\author{
M. Kikawada*, Y. Ichinose ${ }^{\#}$, D. Miyamoto ${ }^{\#}$, K. Minemura\#, M. Takasaki*, K. Toyama
}

Peripheral airway findings in chronic obstructive pulmonary disease using an ultrathin bronchoscope. M. Kikawada, Y. Ichinose, D. Miyamoto, K. Minemura, M. Takasaki, K. Toyama. C ERS Journals Ltd 2000.

ABSTRACT: The authors performed bronchoscopic examination using an ultrathin bronchoscope to determine the characteristics of the peripheral airways in chronic obstructive pulmonary disease (COPD).

The study population comprised 13 healthy control subjects, 10 patients with chronic bronchitis without airflow limitation, and 20 patients with COPD. The COPD patients were divided clinically into 10 with chronic bronchitis and 10 with pulmonary emphysema. The peripheral airways were examined using an ultrathin bronchoscope.

In chronic bronchitis, peripheral airways of the 11th or 12th generation showed a high frequency of obstruction and mucosal changes such as granulation. In pulmonary emphysema, the peripheral airways frequently showed a net-like appearance of the bronchial epithelium and obstruction at the 11th or 12th generation.

Morphological changes of the small airways in chronic obstructive pulmonary disease can be detected by an ultrathin bronchoscope, and this method is likely to be useful for investigating the small airways in vivo.

Eur Respir J 2000; 15: 105-108.
*Geriatric Medicine and "First Dept of Internal Medicine, Tokyo Medical University, Tokyo, Japan.

Correspondence: M. Kikawada, Geriatric Medicine, Tokyo Medical University 6-71, Nishishinjuku Shinjuku-ku, Tokyo 1600023 Japan. Fax: 81333422305

Keywords: Chronic airflow limitation chronic bronchitis

chronic obstructive pulmonary disease pulmonary emphysema

small airway disease

ultrathin bronchoscope (XBF-22L)

Received: December 171998

Accepted after revision August 251999
Chronic obstructive pulmonary disease (COPD) is characterized by the presence of airflow obstruction expressed as reduced maximum expiratory flow $[1,2]$. Diseases such as chronic bronchitis, pulmonary emphysema, and asthmatic bronchitis with airflow limitation are included within the definitions of COPD. In fact, all three conditions may coexist in a single patient. Generally, the peripheral airways of COPD patients are morphologically characterized by several features: hyperplasia of goblet cells, mucous gland hypertrophy, increased intraluminal mucus, increased wall muscle mass, fibrosis, airway narrowing and obliteration, and loss of alveolar attachments to bronchioles [3-5].

All of the previous studies on COPD have been limited in their assessment of the relationship between pathological features and lung function. Bronchoscopy using an ultrathin instrument can be used directly to examine small airways $(<2 \mathrm{~mm})$ in vivo and could potentially provide new information on the airways in COPD. This method allows inspection of the peripheral bronchioles to the 13th order branches, revealing the colour of the bronchial mucosa, morphological changes, existence of secretions, and obstruction. In the present study, the peripheral airways were examined using an ultrathin bronchoscope and COPD subjects were compared with healthy volunteers.

\section{Subjects \\ Materials and methods}

The study population was divided into three groups: 13 healthy control subjects, 10 patients who had chronic bronchitis without airflow limitation, and 20 COPD pa- tients. COPD was diagnosed using the recently published ERS guidelines [2]. The COPD patients were divided clinically into 10 with chronic bronchitis and 10 with pulmonary emphysema. The healthy controls subjects were all nonsmokers with no pulmonary disease on the basis of their past history and no abnormal findings on chest radiography and spirometry.

Chronic bronchitis was defined clinically as cough and sputum production on most days of the month for at least 3 months per year in the previous 2 yrs. The patients with chronic bronchitis comprised 10 with airflow limitation and 10 without airflow limitation.

Pulmonary emphysema was diagnosed by the presence of low attenuation areas on high resolution chest computed tomography (HRCT) scans [6]. The degree of emphysematous change was appraised by visual assessment of HRCT scans [7], and all of the patients with emphysema had moderate or severe emphysema according to this assessment.

Chronic airway obstruction was defined as an forced expiratory volume in one second (FEV1)/vital capacity (VC) of $<88 \%$ of the predicted value in males (or $89 \%$ of the predicted value in females), with a reversibility of $<15 \%$ after inhalation of $200 \mu \mathrm{g}$ of salbutamol. All subjects with chronic bronchitis and pulmonary emphysema were stable. None received systemic corticosteroids or antibiotics during the study and all had a history of chronic bronchodilator therapy (inhaled corticosteroids, anticholinergics, $\beta_{2}$-agonists, etc.). None had had an acute upper respiratory tract infection within 1 month prior to ultrathin flexible bronchoscopy. The study conformed to the Declaration of 
Helsinki and was approved by an appropriate Ethics Committee. Written informed consent was obtained from each subject.

\section{Pulmonary function tests}

Pulmonary function tests were performed with a computerized spirometer (CHESTAC-65V; Chest MI Co., Tokyo, Japan) prior to ultrathin flexible bronchoscopy. The predicted normal values used were obtained from CотеS [8].

\section{Ultrathin bronchoscopy}

All patients underwent peroral bronchofibrescopy (Olympus BF, Type p-8; Olympus Co., Tokyo, Japan) after local anaesthesia of the upper airway with $4 \%$ lignocaine. After observation of the central airways, the bronchofibrescope was wedged into two or three bronchi, and an ultrathin flexible bronchoscope (Olympus XBF-22L; Olympus Co.) was inserted through the biopsy forceps channel to allow observation of the peripheral airways. The XBF-22L had an outer diameter of $1.8 \mathrm{~mm}$ with no channel for biopsy forceps. The central and peripheral airways were assessed for changes of the bronchial walls and for endobronchial abnormalities. Where possible three peripheral airways were inspected and photographed in each patient using the XBF-22L, with care being taken not to injure the bronchial mucosa. The peripheral airways observed were branches of the right lateral basal bronchus (BVIII) and medial basal bronchus (BIX), as well as one of right lateral middle bronchus (BIV) or medial middle bronchus (BV).

\section{Statistical analysis}

The results of pulmonary function tests are expressed as mean \pm SD. Analysis of variance (ANOVA) or Scheffe's test was used for comparison of mean values between the groups. A p-value of $<0.05$ was considered significant.

\section{Results}

\section{Clinical findings}

The clinical characteristics of the subjects are shown in table 1 . There was no significant difference in age, sex, and smoking history between the chronic bronchitis subjects (with or without airflow limitation) and the pulmon- ary emphysema subjects. FEV1 and FEV1/VC percentage of predicted value were significantly lower in the chronic bronchitis subjects with airflow limitation and the pulmonary emphysema subjects than in healthy control subjects or chronic bronchitis subjects without airflow limitation.

\section{Bronchoscopic findings}

All patients were observed and photographed using a conventional bronchofibrescope or the XBF-22L (Olympus Co.). The peripheral airway lesions detected in each group are summarized in table 2 . The detection rate of each peripheral airway finding was expressed as the mean percentage of such abnormalities relative to the total number of bronchi observed in each group. All 13 healthy control subjects had normal bronchial mucosa to the 13th generation bronchial branches (fig. 1).

In all the patients with chronic bronchitis the central airways contained secretions and the peripheral airways also contained secretion continuously from the 5-6th order bronchi to the 11th-12th generation branches. Further, there was a high frequency of obstruction and mucosal irregularities such as granular chanage at the 11th or 12th generation bronchial branches (fig. 2). Obstruction and granular change were observed in $>50 \%$ of the bronchial branches inspected in both groups of patients with chronic bronchitis. Fixed narrowing was also observed in both groups of chronic bronchitis patients, but expiratory collapse of the peripheral airways was a characteristic of chronic bronchitis with airflow limitation.

Patients with emphysema had no abnormalities of the central airways. Their peripheral airways showed marked changes of the bronchial walls, with "net like" appearance and obstruction at the 11th or 12th generation bronchial branches (fig. 3), a pattern detected in $81.8 \%$ of all bronchial branches observed in patients with emphysema. Fixed narrowing was not seen in the subjects with pulmonary emphysema, but expiratory collapse was more severe than in patients who had chronic bronchitis with airflow limitation (although this was only a visual impression).

\section{Discussion}

NiEWOEHNER et al. [9] first reported that cigarette smoking may cause inflammatory reactions such as respiratory bronchiolitis and alveolitis in the peripheral

Table 1. - Clinical and physiological characteristics of the subjects

\begin{tabular}{|c|c|c|c|c|}
\hline & \multirow[t]{2}{*}{ Control } & \multicolumn{2}{|c|}{ Chronic bronchitis } & \multirow[t]{2}{*}{ Pulmonary emphysema } \\
\hline & & without airflow limitation & with airflow limitation & \\
\hline $\mathrm{n}$ & 13 & 10 & 10 & 10 \\
\hline Age yrs & $47(23-72)$ & $68(55-77)^{* *}$ & $69(54-77)^{* *}$ & $65(55-75)^{*}$ \\
\hline Sex M/F & $9 / 4$ & $9 / 1$ & $8 / 2$ & $10 / 0$ \\
\hline Pack-years & 0 & $53.1(0-100)^{* *}$ & $47.5(0-112.5)^{*}$ & $59.1(7.8-140)^{* *}$ \\
\hline FEV1 L & $2.69 \pm 0.41$ & $2.31 \pm 0.37$ & $1.16 \pm 0.41 * * *, \S \S$ & $1.37 \pm 0.66 * * *, s$ \\
\hline FEV $1 \%$ pred & $99.5 \pm 16.7$ & $102.0 \pm 14.1$ & $49.7 \pm 13.7 * * *, \S \S$ & $51.5 \pm 18.3 * * *, \S \S$ \\
\hline $\mathrm{FEV} 1 / \mathrm{VC} \%$ & $77.9 \pm 7.0$ & $70.0 \pm 7.9$ & $42.0 \pm 10.1 * * *, \S \S$ & $42.3 \pm 11.8^{* * *, \S \S}$ \\
\hline FEV1/VC \% pred & $104.2 \pm 9.8$ & $104.5 \pm 10.6$ & $62.5 \pm 14.1^{* * *, \S \S}$ & $62.4 \pm 16.8^{* * *, \S \S}$ \\
\hline
\end{tabular}

Values are expressed as mean \pm SD or absolute number with the range in parentheses. $*: \mathrm{p}<0.05 ; * *: \mathrm{p}<0.01 ; * * *: \mathrm{p}<0.0001$, as compared with the values obtained in healthy control subjects. ${ }^{\S}: \mathrm{p}<0.01 ;{ }^{\S}: \mathrm{p}<0.0001$, as compared with the values obtained in patients with chronic bronchitis without airflow limitation. M: male; F: female; FEV1: forced expiratory volume in one second; VC: vital capacity. 
Table 2. - Endoscopic findings of peripheral airway lesions

\begin{tabular}{|c|c|c|c|c|}
\hline & \multirow{2}{*}{ Control } & \multicolumn{2}{|c|}{ Chronic bronchitis } & \multirow{2}{*}{ Pulmonary emphysema } \\
\hline & & without airflow limitation & with airflow limitation & \\
\hline $\mathrm{n}$ & 13 & 10 & 10 & 10 \\
\hline Reddening & $0 / 38(0)$ & $9 / 31(29.0)^{*}$ & $5 / 31(16.1)$ & $7 / 33(21.2)$ \\
\hline Pallor & $0 / 38(0)$ & $1 / 31(3.2)$ & $6 / 31(19.4)$ & $17 / 33(51.5)^{* * *, \S \S,+}$ \\
\hline Obstruction & $0 / 38(0)$ & $18 / 31(58.1)^{* * *}$ & $16 / 31(51.6)^{* * *}$ & $28 / 33(84.8)^{* * *}$ \\
\hline Ectasia & $0 / 38(0)$ & $2 / 31(6.5)$ & $0 / 31(0)$ & $0 / 33(0)$ \\
\hline Secretions & $0 / 38(0)$ & $25 / 31(80.6)^{* * *}, \# \#$ & 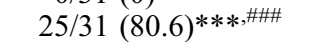 & $10 / 33(30.3)^{* *}$ \\
\hline Pigmentation & $1 / 38(2.6)$ & $4 / 31(12.9)$ & $4 / 31(12.9)$ & $9 / 33(27.2)$ \\
\hline Fixed narrowing & $0 / 38(0)$ & $11 / 31(35.5)^{* *, \#}$ & $13 / 31(41.9)^{* * *, \# \#}$ & $3 / 33(9.1)$ \\
\hline Expiratory collapse & $0 / 38(0)$ & $3 / 31(9.7)$ & $15 / 31(48.4)^{* * *, \S}$ & $22 / 33(66.7)^{* * *, \S \S}$ \\
\hline Granular change & $0 / 38(0)$ & $16 / 31(51.6)^{* * *, \#}$ & $17 / 31(54.8)^{* * *, \# \#}$ & $5 / 33(15.2)$ \\
\hline Net formation & $0 / 38(0)$ & $1 / 31(3.2)$ & $2 / 31(6.5)$ & $27 / 33(81.8)^{* * *, \S \S,+}$ \\
\hline
\end{tabular}

Data are presented as mean percentage in parentheses relative to the total number of bronchi observed. $*: \mathrm{p}<0.05 ; * *: \mathrm{p}<0.01 ; * * *$ : $\mathrm{p}<0.0001$, as compared with the values obtained from healthy control subjects. ${ }^{\S}: \mathrm{p}<0.01{ }^{\S \S}: \mathrm{p}<0.0001$, as compared with the values obtained from patients with chronic bronchitis without airflow limitation. ${ }^{+}: \mathrm{p}<0.0001$, as compared with the values obtained from patients with chronic bronchitis with airflow limitation. ${ }^{\#}: \mathrm{p}<0.05 ;{ }^{\# \#}: \mathrm{p}<0.01 ;{ }^{\# \#}: \mathrm{p}<0.0001$, as compared with the values obtained from patients with pulmonary emphysema.

airways. Smoking is the most important cause of COPD, which is characterized by the presence of airflow obstruction due to chronic bronchitis, pulmonary emphysema, or asthmatic bronchitis [1]. Chronic bronchitis is defined in terms of productive cough and chronic sputum production, and is accompanied morphologically by mucous gland hypertrophy and hyperplasia of goblet cells, increased intraluminal mucus, increased wall muscle mass, fibrosis, airway narrowing and obliteration, and loss of alveolar attachments to bronchioles [3-5]. In contrast, pulmonary emphysema is defined as permanent and destructive enlargement of airspaces distal to the terminal bronchioles without obvious fibrosis [10]. In COPD, chronic bronchitis, pulmonary emphysema and asthma, may coexist in the same patient. Thus, chronic airflow obstruction results from various combinations of peripheral airway lesions due to chronic bronchitis and alveolar lesions due to pulmonary emphysema. However, it is difficult to assess

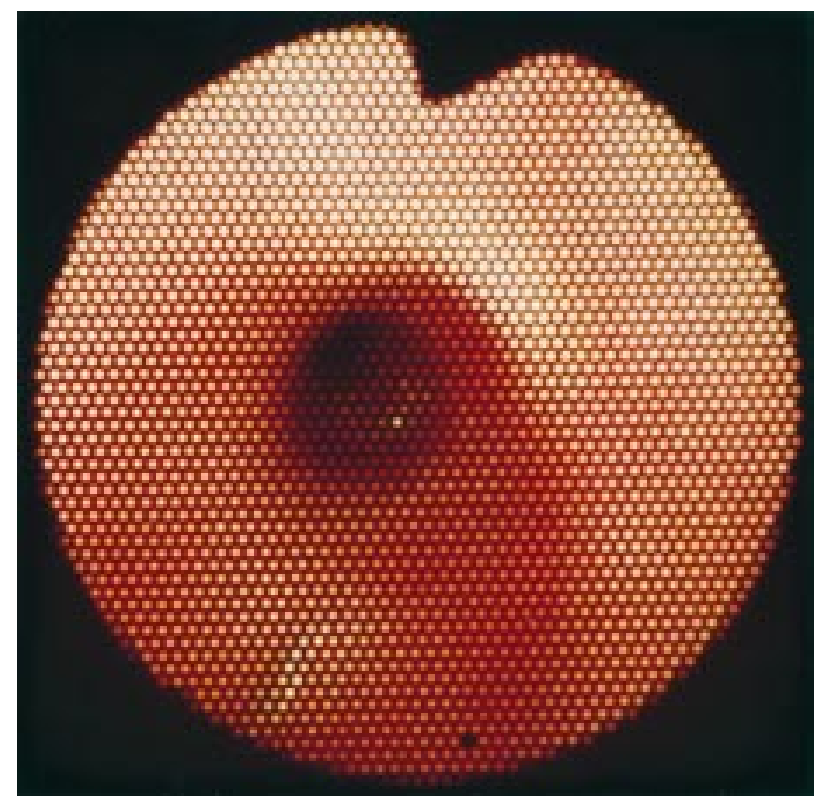

Fig. 1. - Normal peripheral airway at the 13th level of the bronchial branches in a healthy subject. the relative contribution to COPD of emphysema and small airway abnormalities causing fixed expiratory airflow obstruction, and previous studies have been restricted to assessing the relationship between pathological features and lung function. To the best of the authors' knowledge, there has been little research on the peripheral features of small airway disease using an ultrathin flexiable bronchoscope [11-13], and no other study has assessed the peripheral airways in COPD.

This study showed granular changes together with either secretions in the peripheral airways or obstruction at the 11 th or 12th generation bronchial branches in all the patients with chronic bronchitis. Fixed narrowing was also apparent in the peripheral airways, although this was only a visual interpretation. The prevalence of these abnormalities in the peripheral airways did not differ between chronic bronchitis patients with and without airflow limitation, but

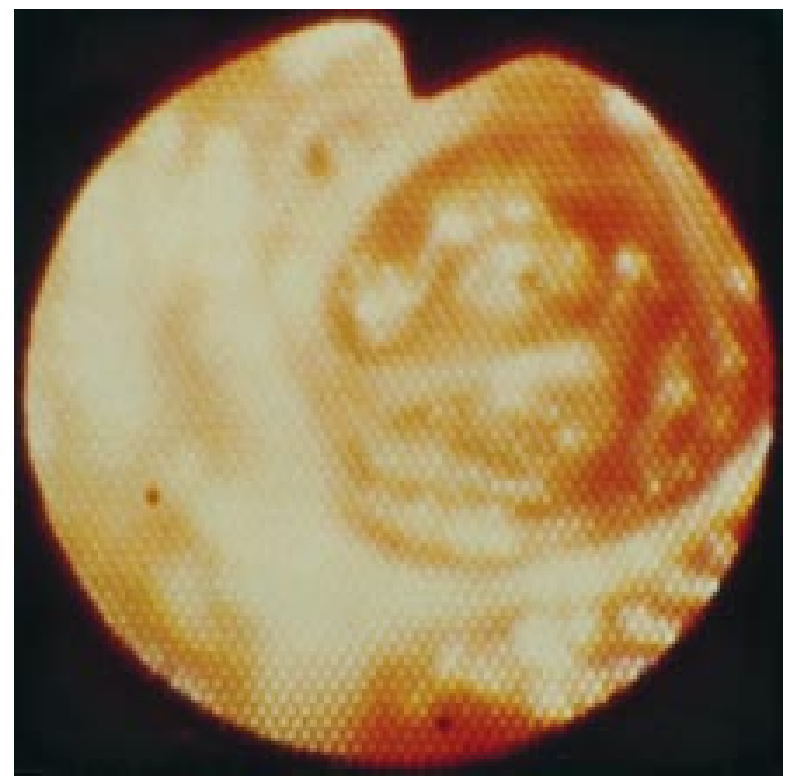

Fig. 2. - Obstruction and an irregular mucosal surface with granular change at the 11th or 12th level of the bronchial branches in a subject with chronic bronchitis. 


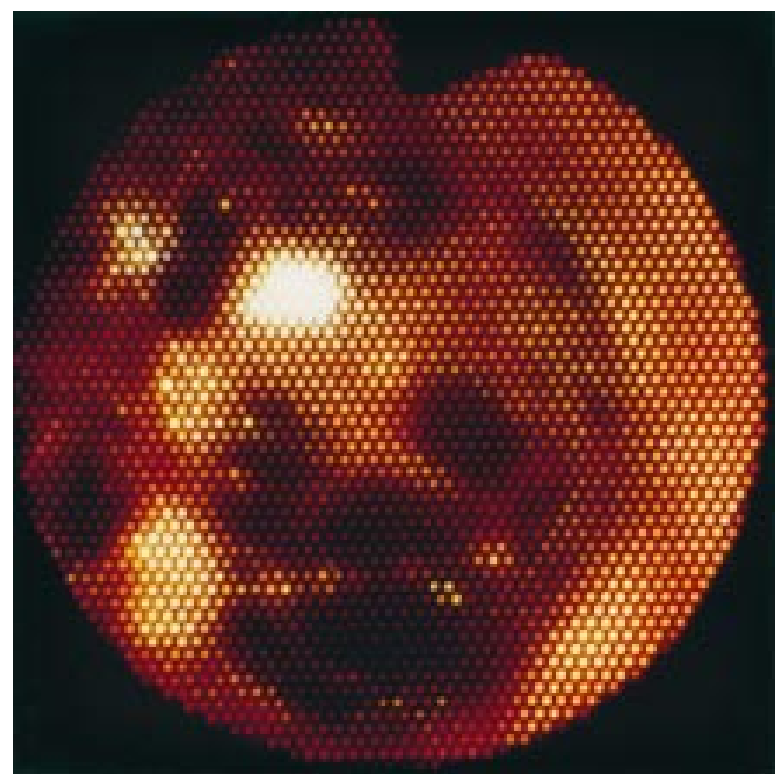

Fig. 3. - Obstruction and marked mucosal changes with a "net like" appearance at the 11th or 12th level of the bronchial branches in a subject with pulmonary emphysema.

expiratory collapse was more common in those with airflow limitation. Epidemiologicial investigations have suggested that chronic hypersecretion and chronic airflow limitation, which are major manifestations of chronic bronchitis, should be regarded as two quite separate disease entities $[14,15]$. The present endoscopic findings in chronic bronchitis seem to support this suggestion.

On the other hand, the main endoscopic feature of pulmonary emphysema in the peripheral airways was net formation at the 11th or 12th generation bronchial branches. Centrilobular emhysema is associated with cigarette smoking and pathological changes occur around the respiratory bronchioles. This study has shown peripheral airway abnormalities in patients with centrilobular emphysema using an ultrathin bronchoscope, so it is possible that these peripheral abnormalities extend to the visible small airways.

Ultrathin bronchoscopy can be used to examine small airways $(<2 \mathrm{~mm})$ in vivo directly and the findings provide new information on COPD. However, the ultrathin bronchoscope has several functional drawbacks that include difficulty in observing the field due to flexibility and difficulty in identifying the generation of bronchial branches in the upper lungs. Furthermore, biopsy of the abnormalities observed by the ultrathin bronchoscope could not be performed, so the morphological changes of the peripheral airways could not be pathologically assessed. The degree of morphological change in the peripheral airways may vary in each bronchial branch, so that endoscopic findings may not reflect the extent of pathological change. Though the ultrathin bronchoscope has several functional drawbacks and limitation in its diagnostic potential, it can give morphological information about the peripheral airways as far as the 11th or 12th generation.

In conclusion, peripheral airway features characteristic of chronic obstructive pulmonary disease could be detected by ultrathin bronchoscopy. It is suggested that granular change in chronic bronchitis and net formation in emphysema are characteristics of the peripheral airways in these conditions.

\section{References}

1. American Thoracic Society Medical Section of the American Lung Association. Standards for the diagnosis and care of patients with chronic obstructive pulmonary disease. Am J Respir Crit Care Med 1995; 152: S77-S120.

2. Siafakas NM, Vermeire P, Pride NB, et al. Optimal assessment and management of chronic obstructive pulmonary disease (COPD). Eur Respir J 1995; 8: 13981420.

3. Cosio MG, Hale KA, Niewoehrier DE. Morphologic and morphometric effects of prolonged cigarette smoking on the small airways. Am Rev Respir Dis 1980; 122: 265271.

4. Wright JL, Hobson JE, Wiggs B, Pare PD, Hoe JC. Airway inflammation and peribronchial attachments in the lungs of nonsmokers, current smokers and ex-smokers. Lung 1988; 166: 277-286.

5. Saetta M, Ghezzo H, Wong DK, et al. Loss of alveolar attachments in smokers: a morphometric correlate of lung function impairment. Am Rev Respir Dis 1985; 132: 894900.

6. Klein JS, Gamsu G, Webb WR, Golden JA, Müller NL. High-resolution CT diagnosis of emphysema in symptomatic patients with normal chest radiographs and isolated low diffusing capacity. Radiology 1992; 182: 817-821.

7. Goddard PR, Nicholson EM, Walt L, Walt I. Computed tomography in pulmonary emphysema. Clin Radiol 1982; 33: 379-387.

8. Cotes JE. Assessment and application in medicine. In: Leathart GL, ed. Lung function. 5th Edn. Oxford, UK, Blackwell Scientific Publications, 1993; pp. 495-498.

9. Neiwoehner DE, Kleinerman J, Rice DB. Patholooic changes in the airways of young cigarette smokers. $N$ Engl J Med 1974; 291: 755-758.

10. Snider GL, Kleinerman J, Thurlbeck WM. The definition of emphysema. Report of a National Heart and Blood Institute, division of lung diseases, Workshop. Am Rev Respir Dis 1985; 132: 182-185.

11. Tanaka M, Kawanami O, Satoh M, Yamaguchi K, Okada Y, Yamasawa F. Endoscopic observation of peripheral airway lesions. Chest 1988; 93: 228-233.

12. Tanaka M, Takizawa H, Satoh M, Okada Y, Yamasawa F, Umeda A. Assessment of an ultrathin bronchoscope that allows cytodiagnosis of small airways. Chest 1993; 106: 1443-1447.

13. Kikawada M, Ichinose Y, Minemura K, Takasaki M, Toyama K. A study of peripheral airway findings using an ultrathin bronchofiberscope and bronchoalveolar lavage fluid with diffuse panbronchiolitis. Respiration 1998; 65: 433-440.

14. Peto R, Speizer FE, Cochrane AL, et al. The relevance in adults of airflow obstruction, but not of mucus hypersecretion, to mortality from chronic lung, disease. Am Rev Respir Dis 1983; 128: 491-500.

15. Anthonisen NR, Wright EC, Hodgkin JE. Prognosis in chronic obstructive pulmonary disease. Am Rev Respir Dis 1986; 133: 14-20. 